Journal for ImmunoTherapy of Cancer

\section{In vivo therapeutic effects of affinity- improved-TCR engineered T-cells on HBV-related hepatocellular carcinoma}

To cite: Liu Q, Tian Y, Li Y, et al. In vivo therapeutic effects of affinity-improvedTCR engineered T-cells on HBV-related hepatocellular carcinoma. Journal for ImmunoTherapy of Cancer 2020;8:e001748. doi:10.1136/ jitc-2020-001748

- Additional material is published online only. To view, please visit the journal online (http://dx.doi.org/10.1136/jitc2020-001748).

Accepted 15 November 2020

Check for updates

(C) Author(s) (or their employer(s)) 2020. Re-use permitted under CC BY-NC. No commercial re-use. See rights and permissions. Published by BMJ.

${ }^{1}$ State Key Laboratory of Respiratory Disease, Guangzhou Institutes of Biomedicine and Health, Guangzhou, China ${ }^{2}$ University of the Chinese Academy of Sciences, Beijing, China

${ }^{3}$ Hefei Institute of Stem Cell and Regenerative Medicine, Guangzhou Institutes of Biomedicine and Health, Hefei, Anhui, China

${ }^{4}$ School of Life Sciences, University of Science and Technology of China, Hefei, Anhui, China

${ }^{5}$ Institute of Physical Science and Information Technology, Anhui University, Hefei, Anhui, China

Correspondence to DrYi Li; li_yi@gibh.ac.cn

\section{ABSTRACT}

Background In patients with hepatitis B virus (HBV)related hepatocellular carcinoma (HCC), virus-specific cytotoxic T lymphocytes (CTLs) fail to eliminate HCC cells expressing HBV antigens. As the expression of viral antigen in HBV-associated HCC may decrease to allow tumor to escape immune attacks, we hypothesized that an HBV surface antigen (HBsAg)-specific affinity-improvedT-cell receptor (TCR) will enable T cells to target HCC more effectively than corresponding wild-type-TCR. We also postulated that TCR promiscuity can be exploited to efficiently capture HBV variants that can hinder CTL-based therapeutics.

Methods We applied flexi-panning to isolate affinityimproved TCRs binding to a variant antigen, the human leukocyte antigen (HLA)-A*02:01-restricted nonapeptide $\mathrm{HBS}_{371-379}$-ILSPFLPLL, from libraries constructed with a TCR cloned using the decapeptide $\mathrm{HBS}_{370-379}$-SIVSPFIPLL. The potency and safety of the affinity-improved-TCR engineered T-cells (Ai-TCR-T) were verified with potentially cross-reactive human and HBV-variant peptides, tumor and normal cells, and xenograft mouse models.

Results Ai-TCR-T cells retained cognate HBV antigen specificity and recognized a wide range of HBV genotypic variants with improved sensitivity and cytotoxicity. Cell infusions produced complete elimination of HCC without recurrence in the xenograft mouse models. Elevated accumulation of $\mathrm{CD}^{+} \mathrm{Ai}$-TCR-T cells in tumors correlated with tumor shrinkage.

Conclusion The in vitro and in vivo studies demonstrated that HBsAg-specific Ai-TCR-T cells had safety profiles similar to those of their wild-type counterparts and significantly enhanced potency. This study presents an approach to develop new therapeutic strategies for HBVrelated $\mathrm{HCC}$.

\section{INTRODUCTION}

Hepatocellular carcinoma (HCC) ranks as the sixth most common cancer and fourth leading cause of cancer-related death worldwide, accounting for nearly 800,000 deaths per year. ${ }^{2}$ Among HCC cases, almost $80 \%$ are associated with chronic hepatitis $\mathrm{B}$ or $\mathrm{C}$ virus (HBV or HCV, respectively) infection. ${ }^{34}$ Current treatments for HCC have a 10-year actual survival rate of only $7.2 \%,{ }^{5}$ and the relapse rate for $\mathrm{HBV}$-positive $\mathrm{HCC}$ is high following liver transplantation. ${ }^{6}$ There is a great demand for potent and tolerable therapies in clinics worldwide.

Although immunotherapies have been considered for HCC, virus-specific T cells are deleted or dysfunctional, and immune attack to eliminate cancer cells is often retarded in patients with HBV-related HCC. ${ }^{7}$ This problem may be overcome with T-cell receptor (TCR)engineered $\mathrm{T}$ cell (TCR-T cell) therapy, ${ }^{8}$ because the viral DNA frequently integrates into the liver cell genome. ${ }^{9} 10$ Whether HCC cells can present any $\mathrm{HBV}$ peptide antigens remains controversial, as there is often no $\mathrm{HBV}$ protein detected in HCC cells with immunohistochemistry (IHC). ${ }^{11}$ However, Tan et $a l^{12}$ recently demonstrated that HBVrelated HCC cells might not express whole $\mathrm{HBV}$ antigens but could transcribe short HBV messenger RNAs encoding epitopes recognized by HBV-specific T cells. Additionally, HBV surface antigen (HBsAg) has been used as a target for TCR-T cells to treat HBVrelated HCC. ${ }^{13}$ An $\mathrm{HBs}_{183-191}$-specific wildtype (WT) TCR, which was isolated from a human leukocyte antigen (HLA)-A2 ${ }^{+}$patient who had resolved an $\mathrm{HBV}$ infection, was shown to recognize HCC cells integrated with natural HBV-DNA and mediate HBV-specific $\mathrm{T}$ cell immunity in vitro and in vivo. ${ }^{14-16}$ As a result, clinical studies of HBsAg-specific $\mathrm{T}$ cell therapy have demonstrated good tolerability and safety with wild-type T-cell receptor (TCR)-engineered T cells (WT-TCR-T). The efficacy of the treatment revealed a volume reduction of several pulmonary HCC metastatic lesions in one of the two patients. ${ }^{12} 1718$

Although $\mathrm{HBV}$ antigen-negative HCC cells can present HBV peptide antigens, the density may be relatively low. ${ }^{19} 20$ TCR-T cells engineered with a wild-type TCR, whose natural affinities are limited to $\sim 1$ to $100 \mu \mathrm{M}$, may not effectively target cells with downregulated tumor antigen presentation. ${ }^{21-26}$ 
However, affinity-improved TCRs can recognize tumor cells presenting low-density antigens. ${ }^{24}$ On the other hand, liver transplantation-treated HCC patients still have a large number of liver tumor cells outside the liver, which may present sparse antigens and contribute to HCC relapse during a later stage. Therefore, we hypothesized that in the treatment of HBV-related HCC, especially in liver-transplanted patients, affinity-improved TCR-engineered T-cells (Ai-TCR-T) will produce better outcomes than WT-TCR-T.

Furthermore, nine HBV genotypes and many variants that have different peptide antigens have been identified to date, ${ }^{27}$ and it would be valuable to create one TCR that can specifically recognize several HBV-variant peptide antigens. It is well documented that a TCR can show promiscuity for recognizing a set of variant antigens, ${ }^{28-31}$ but the T cell maintains physiological specificity in the peripheral immune system. We then questioned whether this feature can be harnessed for the generation of affinity-improved TCRs that are capable of recognizing several HBV variants.

To address both questions, we constructed TCR libraries with a wild-type TCR that was isolated initially with an HLA-A*02:01-restricted HBV genotype-A $\mathrm{HBs}_{370-}$ ${ }_{379}$ (SIVSPFIPLL, named vrt0) decameric peptide antigen complex from a resolved HBV patient. ${ }^{14}{ }^{16}$ Because HBV genotype $\mathrm{C}$ is closely related to an elevated HCC risk, ${ }^{32-35}$ we isolated high-affinity TCRs binding to a genotype $\mathrm{B} / \mathrm{C} / \mathrm{D} \mathrm{HBs}_{371-379}$ (ILSPFLPLL, named vrt1) nonameric peptide antigen from the TCR libraries. An affinityimproved mutant TCR could retain HBsAg specificity similar to the specificity of the wild-type TCR. The mutant TCR constructed Ai-TCR-T cells showed enhanced sensitivity and cytotoxicity in vitro. In addition, Ai-TCR-T cells recognized not only vrt1 and vrt0 but also nine other peptide variants found at high frequencies in HBV species. However, both WT-TCR-T cells and Ai-TCR-T cells were hardly activated by irrelevant peptide-pulsed or potentially cross-reactive human peptide-pulsed cells, human normal primary cells and healthy peripheral blood mononuclear cells (PBMCs), indicating that the Ai-TCR-T cells have a good safety profile. The Ai-TCR-T cells were also demonstrated to eliminate HCG tumors without recurrence in vivo.

\section{METHODS}

\section{$\mathrm{HBs}$ peptides and $\mathrm{HBV}$ genotypes}

$\mathrm{HBs}_{371-379}$ and $\mathrm{HBs}_{370-379}$ epitope sequences were retrieved from 5855 unique full-length HBV surface antigen (HBs) polyproteins (389, 399 and 400AA HBs polyprotein sequences) collected from UniProt around May 2019. First, there were 134 unique nonameric or 190 unique decameric peptides extracted respectively from $\mathrm{HBs}_{371 \text { - }}$ ${ }_{379}$ and $\mathrm{HBs}_{370-379}$ epitope sequences with Strawberry Perl 5.26.1.1 (http://strawberryperl.com) after removing duplication. Second, the most common 20 peptides of $\mathrm{HBs}_{371-379}$ and $\mathrm{HBs}_{370-379}$ were statistically analyzed from unique 5657 (97\% of 5855) and 5528 (94\% of 5855) full-length HBs polyprotein sequences separately. Finally, the most common 20 peptides that already categorized the HBV genotypes in UniProt were statistically analyzed with HBV genotypes. The corresponding HBV genotypes of the most common eight peptides of $\mathrm{HBs}_{371-379}$ (vrt1 to vrt8) and $\mathrm{HBs}_{370-379}$ (vrt0, vrt9 to vrt16) were analyzed with Package 'pheatmap'

(https:// cran.r-project.org/web/packages / pheatmap/index.html) based on statistical software $\mathrm{R}$ V.3.6.1 (https://www.r-project.org/).

\section{Identification of potential cross-reactive human peptides of vrt1 and vrt0}

Potential cross-reactive human peptides were identified by Expitope webserver 2.0 (http://webclu.bio.wzw.tum. de/expitope2/) designed to predict the similar peptides and its potential presentation by the HLA allele of interest. $^{3637}$

For identifying vrt1 and vrt0 related human crossreactive peptides, we combined the results of the alanine scanning to determine the critical TCR binding position of vrt1 and vrt0. The maximum allowed number of mismatches were set as three for vrt1 and four for vrt0 for the primary screening. The chosen allele was HLA$A * 02: 01$. The default parameters were used for the other options. We also carried out a second screening without fixing the critical positions, and the maximum allowed number of mismatches were set two for vrt1 and three for vrt 0 . Those potential peptides derived from proteins with expression data were proceeded the third step of $\mathrm{T}$ cell activation assays.

\section{Antigen peptides}

The 16 most frequent $\mathrm{HBs}_{371-379}$ (HBs371) and $\mathrm{HBs}_{370-}$ ${ }_{379}$ (HBs370) antigenic peptides were retrieved from 5855 full-length HBsAg polyproteins. There were eight HBs371 nonameric peptides, that is, vrt1-ILSPFLPLL, vrt2-ILSPFIPLL， vrt3-ILSPFMPLL， vrt4-ILNPFLPLL, vrt5-IVSPFIPLL, vrt6-TLSPFLPLL, vrt7-ILNPFIPLL and vrt8-IVRPFIPLL, and eight HBs370 decameric peptides, that is, vrt9-NILSPFLPLL, vrt10-NILSPFIPLL, vrt11SILSPFLPLL, vrt12-NILSPFMPLL, vrt13-NILNPFLPLL, vrt14-SILSPFIPLL, vrt0-SIVSPFIPLL and vrt16NILNPFIPLL, that were analyzed (online supplemental figure S1, tables S1.1 and S1.2).

The irrelevant peptide-HLA complexes (pHLAs) (online supplemental table S2) were used to verify the specificity of the TCR mutants. Alanine-scanning peptides and potentially cross-reactive human peptides related to vrt1 and vrt0 (online supplemental tables S3.1 and S3.2) were used to test the binding site and TCR specificity, respectively. All peptides were purchased from Genscript and validated with a mass spectrometer, and the purities were confirmed to be greater than $95 \%$.

Cell lines, PBMC and human normal primary cells

T2, J.RT3-T3.5 cell, 293T and HepG2 were purchased from ATCC. HCC cell lines, PLC/PRF/5 were provided 
by Dr Xiaoping Chen from Guangzhou Institutes of Biomedicine and Health, Chinese Academy of Sciences. PBMC, provided by informed consent healthy donors, are listed in online supplemental table S4 and 12 sets of human primary cells from ScienCell are listed in online supplemental table S5, including human bronchial smooth muscle cells, human aortic smooth muscle cells, human meningeal cells, human renal mesangial cells, human gastric smooth muscle cells, and human renal epithelial cells. Cell culture dish was treated with Poly-LLysine before culturing. All cell lines were authenticated using short tandem repeat profiling and regularly tested negative for mycoplasma contamination throughout the whole duration of this study.

HLA-A2 negative HCC cell line PLC/PRF/5 has multiple, random integrations of $\mathrm{HBV}$ DNA and can express HBsAg. PLC/PRF/5 cells were transduced with HLA-A*02:01 subtype with pLenti-CMV-puro lentivirus vectors to constructed HLA-A*02:01 ${ }^{+}$cell lines. The transduced cells were maintained with the selection of $2 \mu \mathrm{g} / \mathrm{mL}$ puromycin (BD Biosciences). Cells were stained with APCconjugated anti-human-HLA-A2 monoclonal antibody (BioLegend) and positive cells were isolated by sorting on a FACSAria III flow cytometer (BD Biosciences).

\section{Generation and analysis of affinity-improved TCR mutants}

We constructed $V \alpha$ and $V \beta$ chain single-chain TCR variable domain (scTv) evolution libraries using TCR0, which was isolated previously with vrt0-SIVSPFIPLL. The nonapeptide variant vrt1-ILSPFLPLL HBs371-HLA-A*02:01 complex was used as the antigen for bio-panning to isolate affinity-improved TCR variants from the libraries using methods described previously. ${ }^{22}{ }^{38}$ Briefly, the scTv libraries were displayed on the surface of the filamentous bacteriophage M13, and affinity-improved scTv variants were selected with biotinylated vrt1-pHLA captured on streptavidin-coated Dynabeads (Life Technologies). Binding improved scTvs were analyzed in soluble heterodimeric TCR molecules that were purified after refolding Escherichia coli-produced inclusion bodies. The TCR affinities were measured by surface plasma resonance with ProteOn and Biacore.

\section{TCR-T cell construction}

TCR $\alpha / \beta$ chain transgene lentiviral vectors contained a picornavirus $2 \mathrm{~A}$ sequence. In addition, the mouse TCR constant domains replaced the human constant domains to reduce mispairing.

PBMCs, provided by healthy human volunteer donors under Institutional Review Board approved informed consent, were prepared with human Lymphoprep reagent (Axis-Shield). Peripheral blood lymphocytes (PBLs) prepared with the PBMCs were activated with Human T-Activator CD3/CD28 Dynabeads (Life Technologies) at a bead-to-cell ratio of 1:1 in RPMI 1640 medium supplemented with $10 \%$ fetal bovine serum and 100 IU recombinant human IL-2. Lentiviral vectors for WT HBsAg-TCR, affinity-improved HBsAg-TCRs and control-TCR-A6 (a
TCR specific for the HTLV-1 $\operatorname{Tax}_{11-19}$ (LLFGYPVYV)HLA-A*02:01 complex) were transduced into PBLs, which were supplemented with protamine $(10 \mu \mathrm{g} /$ $\mu \mathrm{l})$. After proliferation, T cells were stained with FITCconjugated or APC-conjugated antibodies (BioLegend) for human CD3, CD8, TCR V $\beta 13.1$ or mouse TCR $\beta$-chain, and a PE-conjugated HTLV-1 Tax 11-19 $_{19}$-pHLA or vrt1-pHLA tetramers to verify TCR expression.

\section{T cell activation}

Interferon gamma (IFN- $\gamma$ ) secretion was measured with ELISPOT kits (BD Biosciences). Briefly, $2 \times 10^{3}$ positive TCR-T cells were incubated with T2 cells (HLA-A*02:01 ${ }^{+}$) pulsed with vrt0-vrt16 or irrelevant peptides from human antigens (ranging from $10^{-6}$ to $10^{-13} \mathrm{M}$ ), HCC cells (HLA$\mathrm{A}^{*} 02: 01^{-} \mathrm{PLC} / \mathrm{PRF} / 5$ or HLA-*02:01 ${ }^{+} \mathrm{PLC} / \mathrm{PRF} / 5$ cells $)$, PBMCs or human normal primary cell lines at an effectorto-target (E:T) ratio of 1:10. To compare specificity between WT and affinity-improved TCRs, TCR-T cells were incubated with T2 cells pulsed with the irrelevant antigen SLLMWITQC-HLA-A $* 02: 01$ in a range of $10^{-6}$ to $10^{-13} \mathrm{M}$. The other two negative controls were unpulsed T2 cells and HLA-A*02:01 ${ }^{+} \mathrm{HBsAg}^{-}$HepG2 cells.

\section{T-cell-mediated cytotoxicity}

Cell lysis was determined by releasing lactate dehydrogenase (LDH) with a CytoTox 96 Non-Radioactive Cytotoxicity Assay kit (Promega). T2 cells $\left(5 \times 10^{4}\right)$ pulsed with vrt0-vrt16 (ranging from $10^{-6}$ to $10^{-13} \mathrm{M}$ ) were incubated with an equal amount of TCR-T cells overnight. Unpulsed $\mathrm{T} 2$ and $10^{-6} \mathrm{M}$ irrelevant SLLMWITQC-peptide-pulsed T2 cells were set as negative controls. Cell-line assays were carried out with the HCC cell line PLC/PRF/5 transduced with HLA-A*02:01 at an E:T ratio of $1: 1$ and 3:1, and the controls were HLA-A*02:01- PLC/PRF/5 cells and HBsAg ${ }^{-}$HLA-A*02:01 ${ }^{+}$HepG2 cells. Experiments were performed in triplicate.

\section{Mouse xenograft models}

Immunodeficient male NOD/SCID IL2 $\mathrm{rg}^{-/-}$(NSI) mice aged 6 to 9 weeks were provided by Dr Peng Li at the Guangzhou Institutes of Biomedicine and Health, CAS. ${ }^{39}$ Mice were maintained with daily monitoring under controlled sterile environment conditions on a 12 hours light/dark cycle, and received a rodent diet sterilized with $60 \mathrm{Co}-\gamma$-ray irradiation and sterilized water. Experimental protocols were approved by the Institutional Animal Care and Use Committee (IACUC). Each mouse was injected subcutaneously with $3.0 \times 10^{6}$ HLA-A $* 02: 01^{+}$PLC/PRF $/ 5$ HCC cells on day 0 . After the tumors reached nearly $60 \mathrm{~mm}^{3}$ (day 13), the mice were randomly assigned to groups and treated with phosphate-buffered solution (PBS), $3.0 \times 10^{7}$ TCR-A6-T cells, 3.0 $\times 10^{7}$ TCR0-T cells or $3.3 \times 10^{6}, 1.0 \times 10^{7}$ or $3.0 \times 10^{7}$ TCR15-T cells via tail vein injection. Tumor volumes were measured every 3 days. From the criteria of IACUC, for subcutaneous tumors the maximum allowable size is $20 \mathrm{~mm}$ in diameter for a mouse. So, on day 34 , the tumor-bearing mice were 
Table 1 The affinities of mutated TCRs isolated from TCRO (WT) mutation libraries*

\begin{tabular}{|c|c|c|c|c|c|}
\hline \multirow[b]{2}{*}{ TCR no. } & \multicolumn{3}{|c|}{ TCR and the vrt1-pHLA } & \multirow[b]{2}{*}{$\mathrm{K}_{\mathrm{D}}-\mathrm{TCR} 0 / \mathrm{K}_{\mathrm{D}}-\mathrm{TCR} 15$} & \multirow[b]{2}{*}{ Mutated sequeces of TCR $\alpha$ CDR3 } \\
\hline & $K_{a}(1 / M s)$ & $K_{d}(1 / s)$ & $K_{D}(M)$ & & \\
\hline TCRO (WT) & $2.58 \mathrm{E}+05$ & $8.78 \mathrm{E}-01$ & $3.40 \mathrm{E}-06$ & 1.0 & NLYAG \\
\hline TCR2 & $2.54 \mathrm{E}+05$ & $3.85 \mathrm{E}-02$ & $1.51 \mathrm{E}-07$ & 22.5 & ADQSR \\
\hline TCR3 & $2.55 \mathrm{E}+05$ & $1.11 \mathrm{E}-01$ & 4.36E-07 & 7.8 & QDPSK \\
\hline TCR6 & $1.37 \mathrm{E}+05$ & $3.44 \mathrm{E}-01$ & $2.51 \mathrm{E}-06$ & 1.4 & QDPTN \\
\hline TCR7 & $1.66 \mathrm{E}+05$ & $2.42 \mathrm{E}-01$ & $1.46 \mathrm{E}-06$ & 2.3 & QDSSR \\
\hline TCR8 & $2.76 \mathrm{E}+05$ & $3.47 \mathrm{E}-01$ & $1.26 \mathrm{E}-06$ & 2.7 & QDPAK \\
\hline TCR9 & $2.37 \mathrm{E}+05$ & $2.57 \mathrm{E}-01$ & $1.09 \mathrm{E}-06$ & 3.1 & QEPSR \\
\hline TCR13 & $1.27 \mathrm{E}+05$ & $3.27 \mathrm{E}-01$ & $2.58 \mathrm{E}-06$ & 1.3 & QHPAT \\
\hline TCR14 & $2.59 \mathrm{E}+05$ & $1.57 \mathrm{E}-01$ & $6.09 \mathrm{E}-07$ & 5.6 & ADPSK \\
\hline TCR15 & $3.84 \mathrm{E}+05$ & $1.77 \mathrm{E}-01$ & $4.61 \mathrm{E}-07$ & 7.4 & AHPSK \\
\hline TCR16 & $1.73 E+05$ & 2.97E-01 & $1.72 \mathrm{E}-06$ & 2.0 & QSPDQ \\
\hline TCR17 & 1.17E+05 & $2.82 \mathrm{E}-01$ & $2.42 \mathrm{E}-06$ & 1.4 & QDPAS \\
\hline TCR18 & $1.30 \mathrm{E}+05$ & 2.27E-01 & $1.74 \mathrm{E}-06$ & 2.0 & QDPSH \\
\hline TCR19 & $9.50 \mathrm{E}+04$ & 2.34E-01 & $2.46 \mathrm{E}-06$ & 1.4 & QDPST \\
\hline
\end{tabular}

*The antigen binding affinities of TCR mutants were determined with ProteOn analysis, and the change over the WT-TCR affinity is indicated.

pHLA, peptide-HLA complexes; TCR, T-cell receptor; WT, wild-type.

euthanized by cervical dislocation, and tumor tissues were resected and weighed.

\section{Detection of human T cells in tumors}

Histological HCC tumor sections were stained with H\&E or antibodies for IHC. Primary anti-human CD3 (Dako) and anti-human CD8 (ZSGB-BIO) monoclonal antibodies and Dako REAL EnVision Detection System were used for IHC, and DAPI (blue) stained nuclei. The sections were imaged with a LAIKA2500, and cell numbers were calculated with Image-Pro Plus 6.0.

\section{RESULTS}

\section{Selection and analysis of affinity-improved TCRs}

Commonly, phage display bio-panning for affinity improvement applies the antigens used for the isolation of WT molecules to maintain specificity. However, TCR binding shows a certain degree of promiscuity. Therefore, the nonameric antigen vrt1-ILSPFLPLL PHLA, the variant of decameric antigen vrt0-SIVSPFIPLL used to isolate the WT TCR, was employed for affinity evolution, and we named this kind of selection flexi-panning. Nineteen TCR variants with CDR3 $\alpha$ mutations were identified and showed affinity-improved binding to the vrt1-pHLA (table 1).
Compared with TCR0-T cells (WT), TCR6-T, TCR11-T, TCR14-T, TCR15-T, TCR17-T and TCR19-T cells were Ai-TCR-T cells that could be specifically activated by $\mathrm{T} 2$ cells pulsed with relatively low-level antigens (figure 1A,B). Four TCR variants demonstrated stronger capabilities than WT TCR0 for redirecting T cells, with TCR14-T, TCR15-T, TCR17-T and TCR19-T cells showing significantly better half maximal effective concentration $\left(\mathrm{EC}_{50}\right)$ values. TCR14-T cells and TCR15-T cells showed the best activation with the HLA-A*02:01 ${ }^{+}$PLC/PRF/5cell line (figure 1C) despite showing relatively little improvement in the $\mathrm{EC}_{50}$ by peptide titration (online supplemental table S6).

\section{Characteristics of TCR15 and enhanced cytotoxicity of TCR15-T cells}

TCR14-T and TCR15-T cells exhibited strong cytotoxicity, as measured by assessing the lysis of vrt1-pulsed T2 cells (figure 2A,B). However, only TCR15-T cells showed specific cytotoxicity with minimal background cytotoxicity. The $\mathrm{EC}_{50}$ of vrt1-pulsed T2 cell lysis by TCR15-T cells was nearly 38 -fold better than that by TCR0-T cells (online supplemental figure S2). When HBsAg-specific cytotoxicity was investigated by targeting HLA-A*02:01 ${ }^{+}$ PLC/PRF/5 HCC cell lines, both WT-TCR-T cells and Ai-TCR-T cells exhibited dose-dependent target cell lysis, 

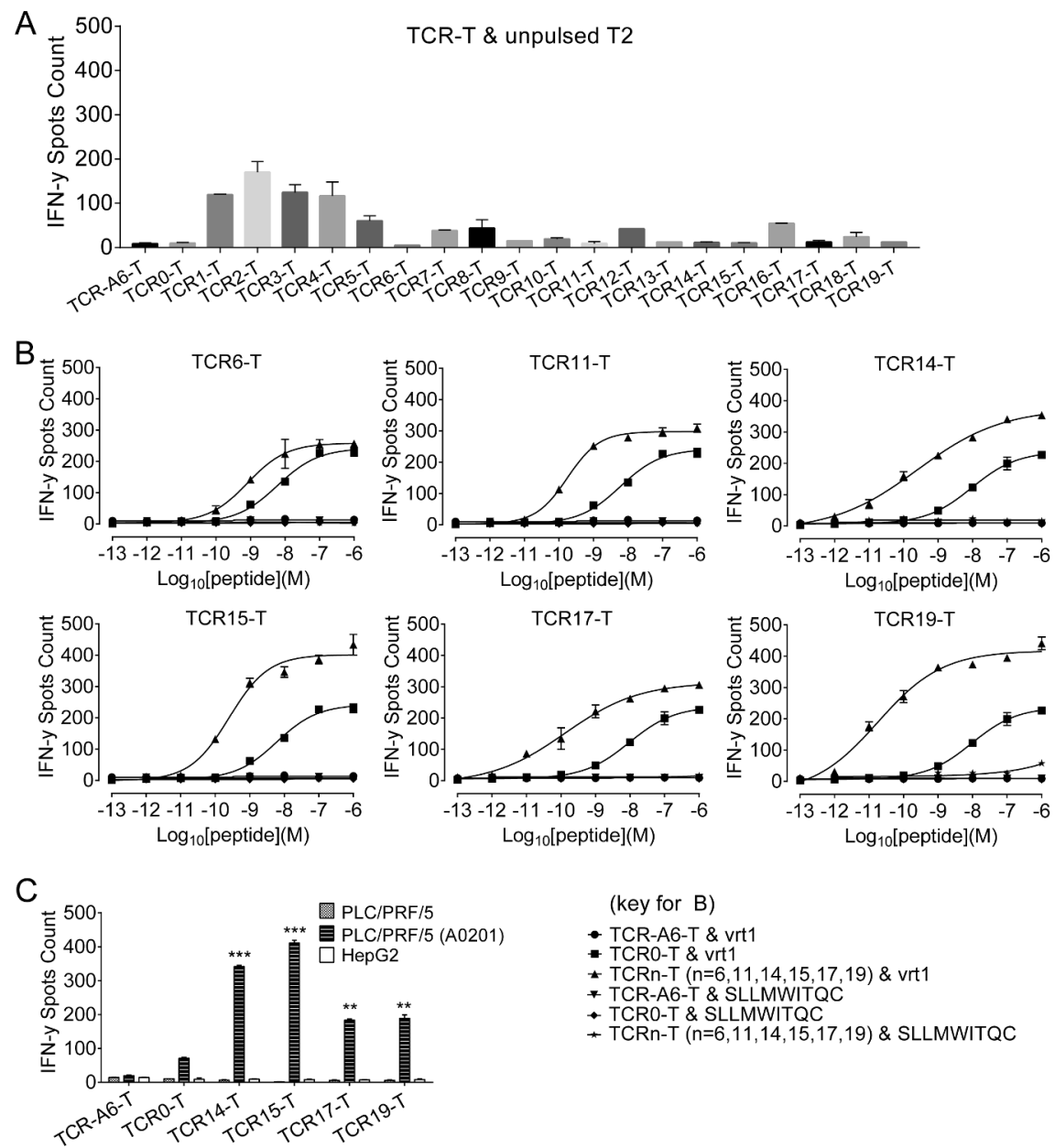

(key for B)

- TCR-A6-T \& vrt1

- TCRO-T \& vrt1

TCRn-T $(\mathrm{n}=6,11,14,15,17,19) \& \mathrm{vrt}$

* TCR-A6-T \& SLLMWITQC

- TCRn-T $(n=6,11,14,15,17,19) \&$ SLLMWITQC

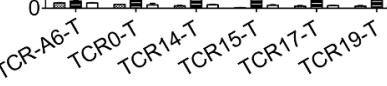

Figure 1 Analysis of TCR-T cell activation by measuring IFN- $\gamma$ release. All samples were set up in triplicate and evaluated after coculturing cells overnight at an E:T ratio of 1:10. (A) To verify specificity, 19 affinity-improved TCR-engineered T cells (Ai-TCR-T cells) were incubated with unpulsed T2 cells overnight to detect IFN- $\gamma$ release. (B) T2 cells pulsed with vrt1 (concentration range: $10^{-6}$ to $10^{-13} \mathrm{M}$ ) were incubated with Ai-TCR-T cells. T2 cells pulsed with an irrelevant peptide $\left(10^{-6}\right.$ to $\left.10^{-12} \mathrm{M}\right)$ were the negative control. (C) IFN- $\gamma$ release was measured after TCR-T cells were incubated with HLA*A-02:01- PLC/PRF/5 or HLA-A $02: 01^{+} \mathrm{PLC} / \mathrm{PRF} / 5 \mathrm{HCC}$ cells. The negative controls were HBsAg-negative HepG2 cells and TCR-A6-T cells. ${ }^{*} \mathrm{p}<0.05$, ${ }^{* *} \mathrm{p}<0.01,{ }^{* \star *} \mathrm{p}<0.001$. E:T, effector-to-target; HBsAg, HBV surface antigen; HBV, hepatitis B virus; HLA, human leukocyte antigen; IFN- $\gamma$, interferon gamma; TCR, T-cell receptor; TCR-T, TCR-engineered T cell.

and TCR15-T cells caused significantly enhanced LDH release compared with TCR0-T cells (figure 2C).

These data demonstrated TCR15 transduced T cells with acceptable activation, killing potency and specificity. Peptide vrt0-isolated TCR0 was compared with vrt1-pHLA-isolated TCR15 for binding to the two distinct antigens by Biacore. The mutant TCR15 had over sevenfold and fivefold higher binding affinities for the variant vrt1-pHLA and the original vrt0-pHLA antigens, respectively (table 2). TCR15 also demonstrated modest affinity enhancement for binding to vrt0-pHLA, despite vrt1pHLA being used as the ligand for molecular evolution. This result revealed that flexi-panning could maintain the original affinity pattern of the TCR.

\section{Specificity and safety of TCR15-T cells}

The specificity of TCR 0 and TCR 15 was verified, and these TCRs showed no binding with a panel of irrelevant pHLAs (online supplemental table S2). A three-step approach for an in-depth study was carried out for potential cross reactivity on relevant pHLAs; the first step involved alanine scanning of vrt0 and vrt1, the second step involved searching for cross-reactive antigens in the available human proteome expression data (online supplemental tables S3.1 and S3.2), and the third step involved verifying these antigens with pulsed T2 cells. Safety was measured with a panel of normal cells. Based on the cell activation showed in the alanine scanning, the residue positions F5 and L8 of vrt1 and F6 and L9 of vrt0 are crucial for maintaining the interactions between the TCR and HBsAg peptide-pulsed HLA-A*02:01 ${ }^{+}$T2 cells (online supplemental figure S3A,B). We identified a total of 33 vrt1-related potentially cross-reactive human peptides, 1 of which contained 2 mismatch residues and 32 of which contained 3 mismatches plus invariable F5 and L8 residues. For vrt0, we identified 2 sequences containing 2 or 3 mismatches and 10 sequences 
A

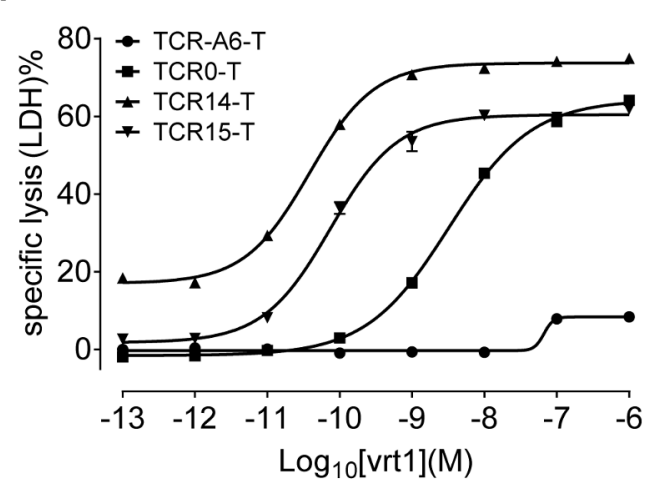

B

$$
\mathrm{E}: \mathrm{T}=1: 1
$$

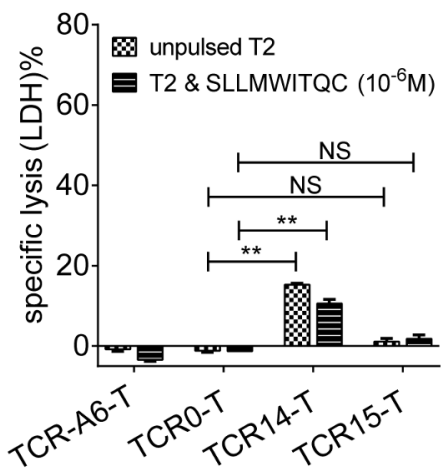

$E: T=3: 1$
$\mathrm{E}: \mathrm{T}=1: 1$

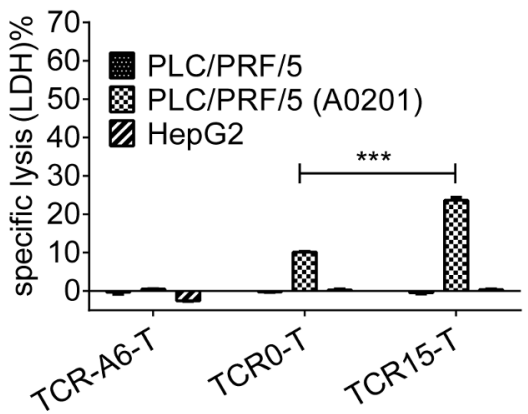

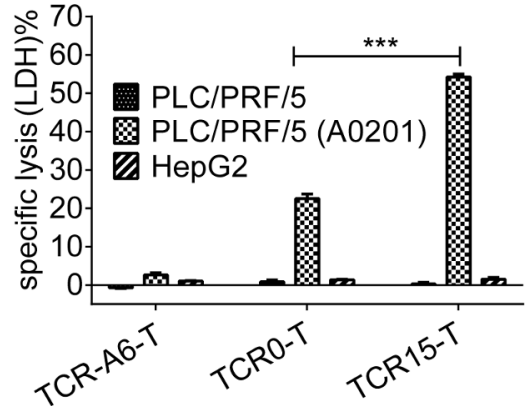

Figure 2 Detection of TCR-T cell cytotoxicity. (A) Cytotoxicity assays were performed by incubating TCR-T cells with T2 cells pulsed with vrt1 $\left(10^{-6}\right.$ to $\left.10^{-13} \mathrm{M}\right)$ at an E:T ratio of 1:1. (B) To verify specificity, LDH release was also measured for unpulsed and irrelevant peptide-pulsed T2 cells. (C) Cytotoxicity of LDH release was determined after incubating TCR-T cells with $\mathrm{HLA}^{*} \mathrm{~A}-02: 01^{-}$or $\mathrm{HLA}^{*} \mathrm{~A}-02: 01^{+} \mathrm{PLC} / \mathrm{PRF} / 5 \mathrm{HCC}$ cell lines at an E:T ratio of $1: 1$ or $3: 1$. The negative controls were $\mathrm{HBs} \mathrm{Ag}$ negative HepG2 cells and TCR-A6-T cells. All assays were performed in triplicate. ${ }^{*} p<0.05,{ }^{* \star} p<0.01,{ }^{* * *} p<0.001$. E:T, effectorto-target; HBsAg, HBV surface antigen; HBV hepatitis B virus; LDH, lactate dehydrogenase; TCR, T-cell receptor; TCR-T, TCRengineered $\mathrm{T}$ cell.

containing 4 mismatches with fixed F6 and L9 residues. All 45 potentially cross-reactive candidates were verified for agonist capabilities on peptide-pulsed T2 cells over a concentration range from $10^{-6}$ to $10^{-8} \mathrm{M}$. We found that most of these peptides, except high concentration $\left(10^{-6}\right.$ and $10^{-7} \mathrm{M}$ ) vrt1-L1, vrt1-L5, vrt1-L12, and vrt1-L19, which mainly derived from poorly expressed proteins, showed no agonist capability (figure 3A,B, online supplemental figure S4). TCR0-T cells but not TCR15-T cells appeared to be activated by T2 cells pulsed with vrt1-L13 derived from a poorly expressed protein.
To verify TCR-T cell specificity with primary cells, TCR15-T and TCR0-T cells were tested and showed no activation by any PBMCs from 30 different healthy donors (figure 3C, online supplemental table S4). Further verification of the TCR15-T cell interactions with antigens presented by normal cells was carried out with 12 sets of human primary cells (online supplemental table S5). These normal cells could not activate TCR0-T or TCR15-T cells (figure 3D).

In summary, these results demonstrated that TCR15-T cells showed HBsAg specificity similar to that of WT-TCR-T

Table 2 The affinities of TCR0 and TCR15 for the vrt1-pHLA and vrt0-pHLA*

\begin{tabular}{|c|c|c|c|c|}
\hline \multirow[b]{2}{*}{ TCR no. } & $\mathrm{K}_{\mathrm{a}}(1 / \mathrm{Ms})$ & $K_{d}(1 / s)$ & $K_{D}(M)$ & \multirow[b]{2}{*}{$\mathrm{K}_{\mathrm{D}}-\mathrm{TCR} 0 / \mathrm{K}_{\mathrm{D}}-\mathrm{TCR} 15$} \\
\hline & \multicolumn{3}{|c|}{ Binding to the vrt1-pHLA } & \\
\hline TCRO (WT) & $4.91 \mathrm{E}+05$ & $2.68 \mathrm{E}+00$ & $5.46 \mathrm{E}-06$ & 1.0 \\
\hline TCR15 & \multicolumn{3}{|c|}{ Binding to the vrt0-pHLA } & \\
\hline TCRO (WT) & $3.58 \mathrm{E}+05$ & 7.76E-01 & $2.17 \mathrm{E}-06$ & 1.0 \\
\hline
\end{tabular}

*The affinities of the TCRs were determined with Biacore 4000, and the change over the affinity of the wild-type molecule TCR0 is indicated. pHLA, peptide-HLA complexes; TCR, T-cell receptor; WT, wild-type. 

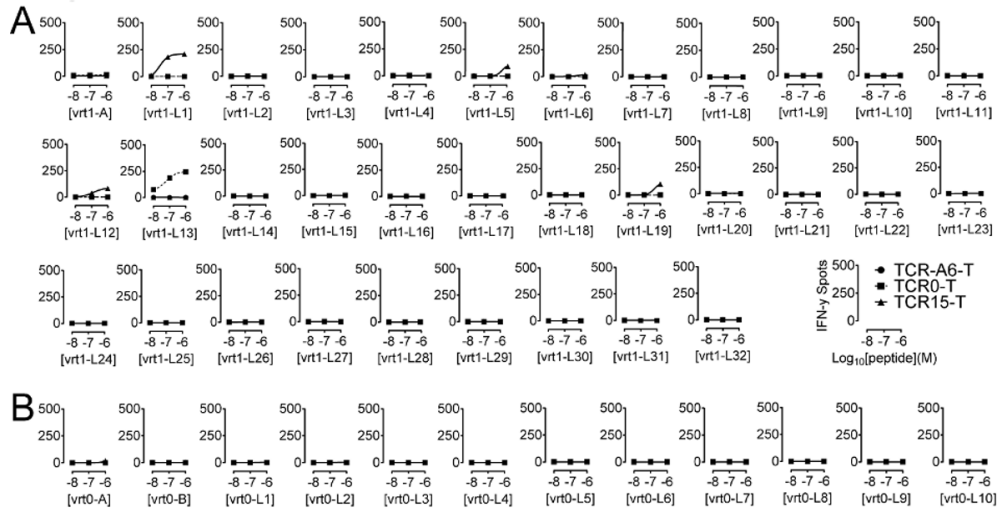

C $400+1$
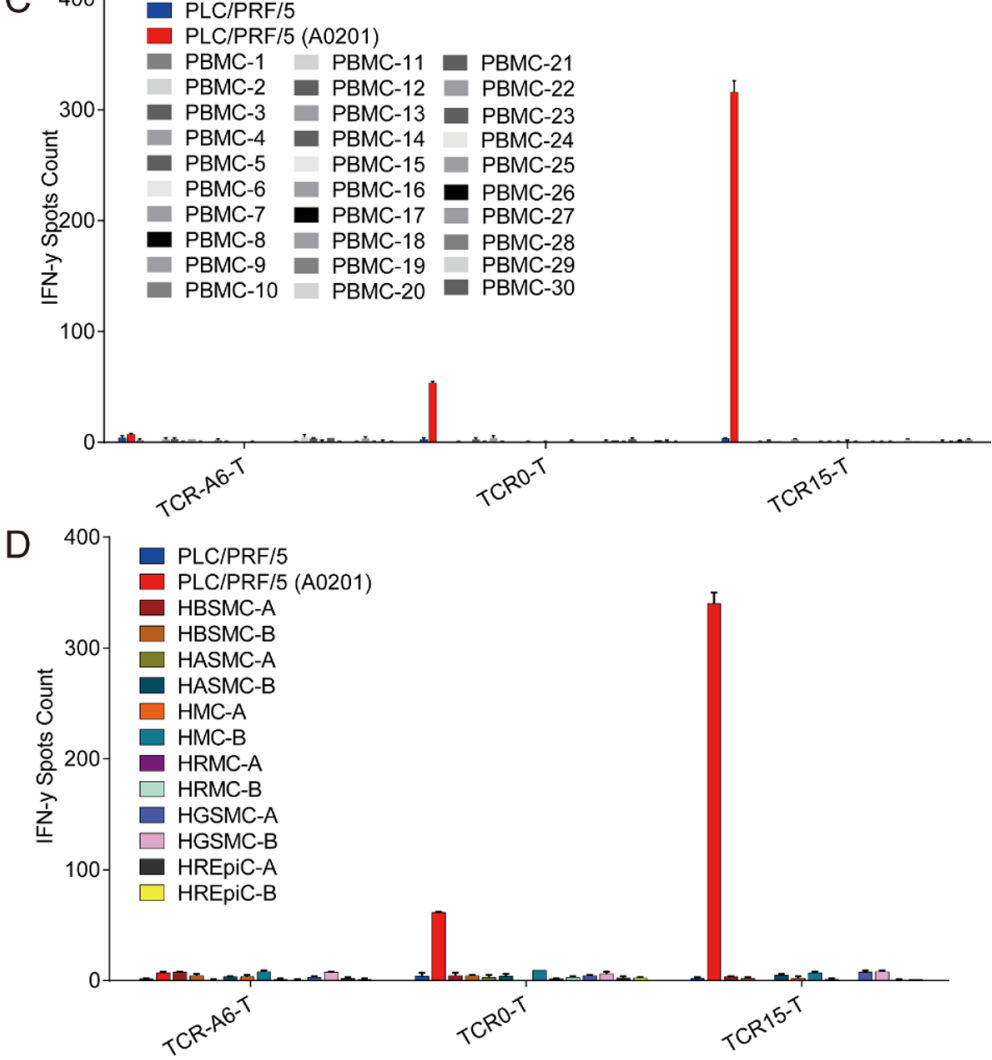

Figure 3 Verification of potentially cross-reactive human peptide antigens of vrt 1 and vrt0, and interactions between TCR-T cells and PBMCs or human normal primary cells. After coculturing TCR-T cells with potentially cross-reactive human peptides $\left(10^{-6}\right.$ to $\left.10^{-8} \mathrm{M}\right)$-pulsed T2 cells, PBMC and human normal primary cells in triplicate overnight at an E:T ratio of 1:10, IFN- $\gamma$ release was detected. There were 33 peptides related to vrt1 (A),12 peptides related to vrt0 (B), 30 healthy PBMC sets (C) and 12 human normal primary cell sets (D). The negative and the positive controls were PLC/PRF/5 cells and HLA-A*02:01 ${ }^{+} \mathrm{PLC} /$ PRF/5 cells, respectively. E:T, effector-to-target; HASMC, human aortic smooth muscle cells; HBSMC, human bronchial smooth muscle cells; HGSMC, human gastric smooth muscle cells; HLA, human leukocyte antigen; HMC, human meningeal cells; HREpiC, human renal epithelial cells; HRMC, human renal mesangial cells; IFN- $\gamma$, interferon gamma; PBMCs, peripheral blood mononuclear cells; TCR, T-cell receptor; TCR-T, TCR-engineered T cell.

cells and at least an equivalent safety profile under a range of measurements.

\section{TCR15-T cells had improved recognition of HBs370 and HBs371 variants}

The specificity of flexi-panning-generated TCRs was measured with HBs371 and HBs370 variants (online supplemental figure S1, tables S1.1 and S1.2). Approximately 5855 unique full-length HBsAg protein sequences were collected from UniProt, and 16 of the most frequent
HBs371- and HBs370-variant peptides represented approximately $90 \%$ of the sequences, that is, vrt1 to vrt8 were nonamer $\mathrm{HBs} 371$ variants, and vrt 0 , vrt 9 to vrt 16 were decamer HBs370 variants. Results for IFN- $\gamma$ (figure 4A,B) and $\mathrm{LDH}$ release (figure 4C,D) showed that both WT and affinity-improved TCRs were able to endow $\mathrm{T}$ cells with the ability to recognize 11 of the 16 variants, excluding vrt4, vrt7, vrt8, vrt13 and vrt16. Epitope sequence analysis of these five non-stimulating peptides indicated that the 


\section{A}
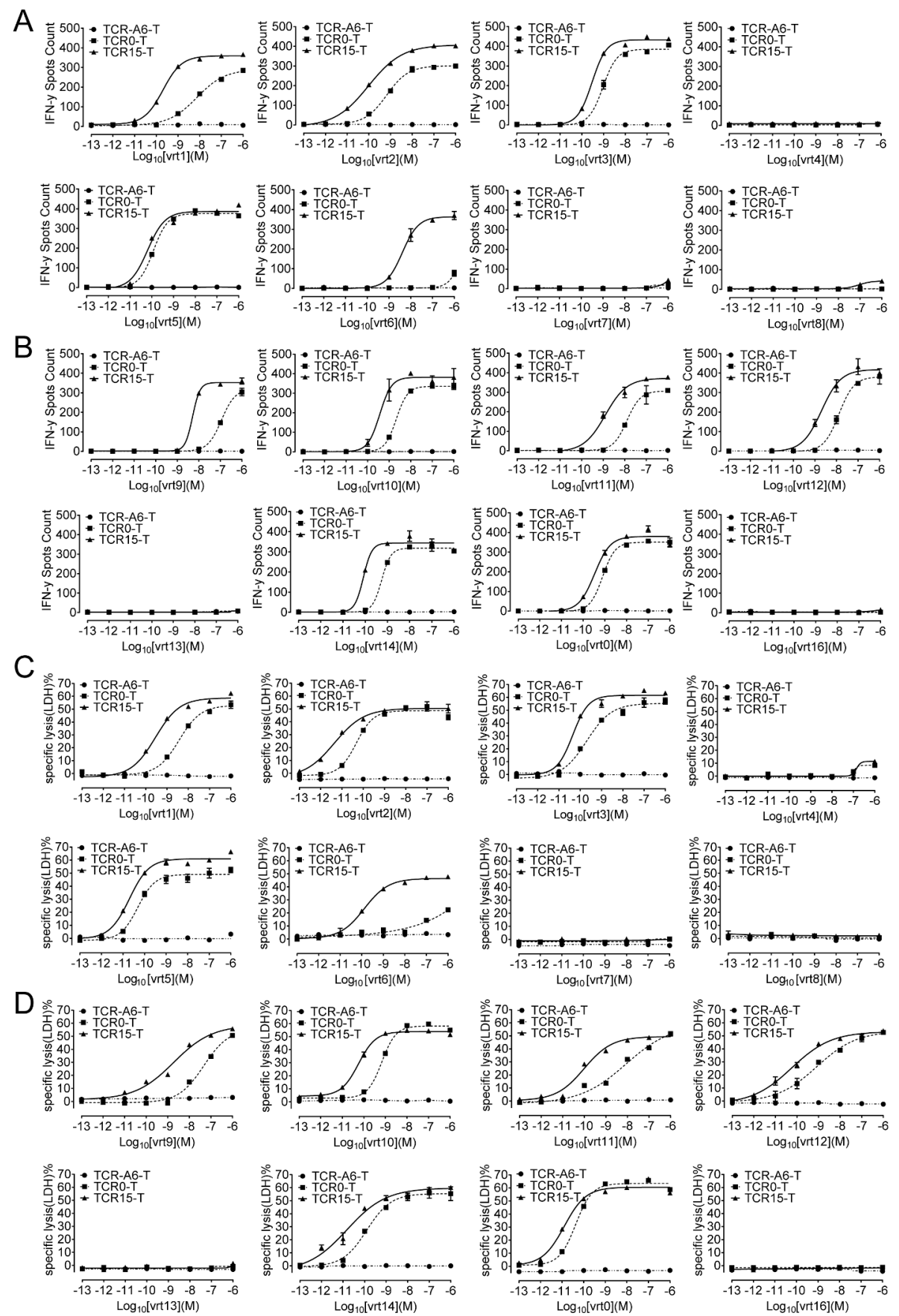

Figure 4 Determination of TCR-T cell activation by and cytotoxicity to T2 cells pulsed with viral peptide variants. T2 cells pulsed with an HBsAg epitope variant peptide $\left(10^{-6}\right.$ to $\left.10^{-13} \mathrm{M}\right)$ were incubated with TCR-T cells overnight at an E:T ratio of 1:10. IFN- $\gamma$ release was detected for vrt1-8 (A) and vrt0, vrt9-16 (B) with an ELISPOT kit. Measuring LDH release showed the percentages of specific lysis of vrt1-8 (C) and vrt0, vrt9-16 (D) (10 $10^{-6}$ to $\left.10^{-13} \mathrm{M}\right)$ pulsed T2 cell, which were incubated with TCR0-T or TCR15-T cells at an E:T ratio of 1:1 overnight. E:T, effector-to-target; HBsAg, HBV surface antigen; HBV, hepatitis B virus; IFN- $\gamma$, interferon gamma; LDH, lactate dehydrogenase; TCR, T-cell receptor; TCR-T, TCR-engineered T cell.

Ser at position three in the nonapeptide and position four in the decapeptide would be the key in the epitope. Ser is allowed at this position, while Asn or Arg will abolish the binding to the TCR. Additionally, comparing $\mathrm{EC}_{50}$ values made it very clear that the variant-mediated activation and cytotoxicity of TCR15-T cells were better than those of TCR0-T cells. This was consistent with the TCR affinity improvement (online supplemental table S7). Especially for vrt6, TCR15-T cells showed over 1000-fold enhancement than TCR0-T cells, which indicated no control of infection with HBV containing vrt6 variant. In conclusion, TCR15-T cells exhibited enhanced killing of T2 cells presenting the 11 most frequent variant peptides.

\section{TCR15-T cells could eradicate HCC xenograft tumors}

To verify whether improving TCR affinity affects in vivo tumor suppression, TCR0-T and TCR15-T cells were evaluated in xenograft mouse models established with 

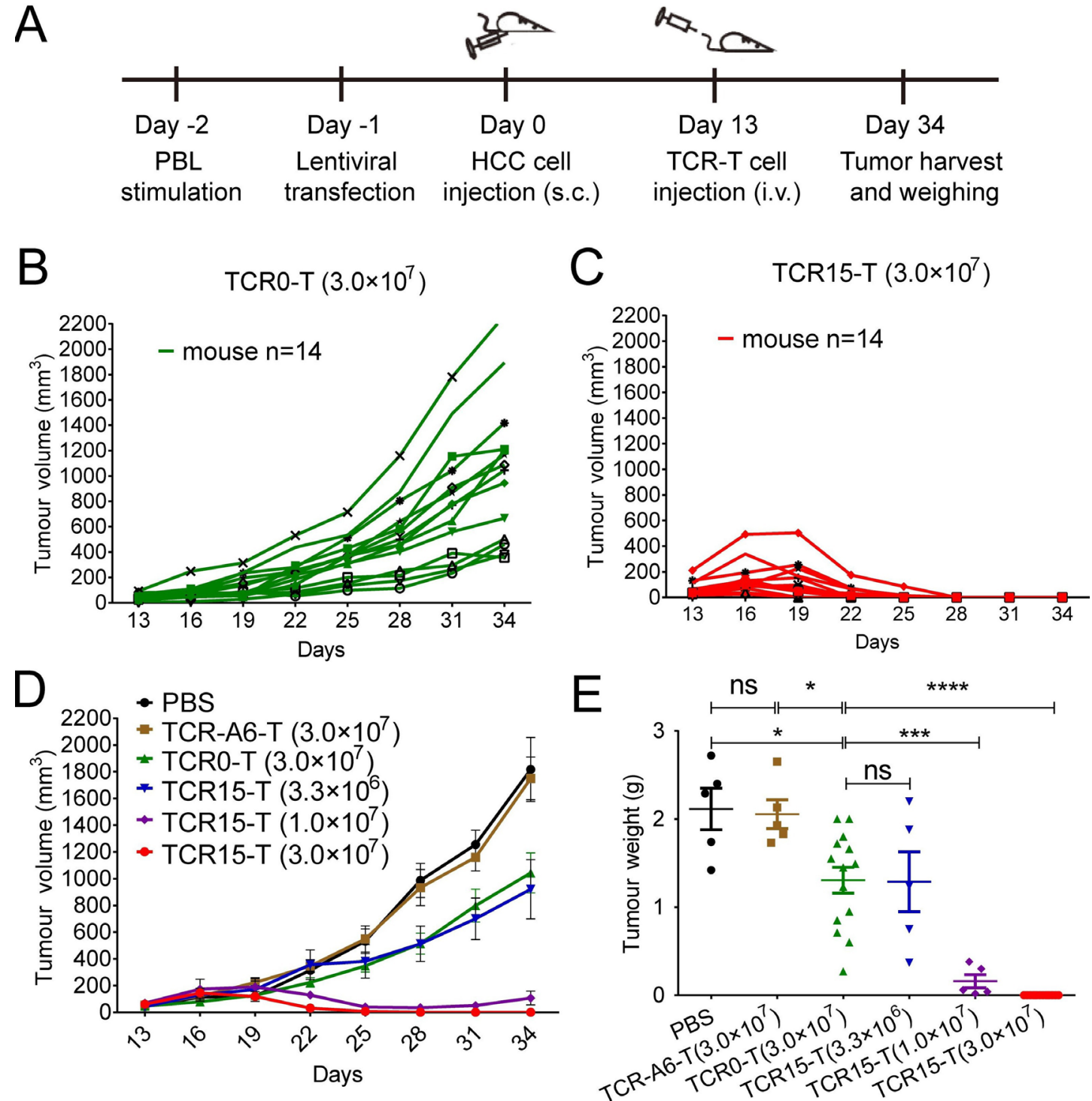

Figure 5 TCR15-T cells could eradicate HBV-related HCC in xenograft NSI mouse models. (A) Experimental setup. Tumor growth curves of individual mice grouped by treatment with (B) TCRO-T cells $\left(3.0 \times 10^{7}\right)$ or $\left(\right.$ C) TCR $15-T$ cells $\left(3.0 \times 10^{7}\right)$, mice $(n=14)$. (D) Mean tumor growth curves of six groups. Tumor volume was calculated every 3 days with the formula (length $\times$ width ${ }^{2}$ 12. PBS, 3.0 $\times 10^{7}$ TCR-A6-T cells, $3.3 \times 10^{6}$ or $1.0 \times 10^{7}$ TCR15-T cells, mice $(n=5)$. (E) Statistical comparison of tumor weights among the xenograft model groups. The pooled results of three independent experiments are shown. Error bars denote the SEM, and groups were compared with a two-sided, unpaired t-test. ${ }^{*} \mathrm{p}<0.05,{ }^{* *} \mathrm{p}<0.01,{ }^{* * *} \mathrm{p}<0.001,{ }^{* * *} \mathrm{p}<0.0001$. HBV, hepatitis $B$ virus; HCC, hepatocellular carcinoma; i.v., intravenous; PBL, peripheral blood lymphocyte; PBS, phosphate-buffered solution; s.c., subcutaneous; TCR, T-cell receptor; TCR-T, TCR-engineered T cell.

HLA-A $* 02: 01^{+}$PLC/PRF/5 HCC cells, which expressed the HBs371 nonapeptide antigen vrt2 and HBs370 decapeptide antigen vrt10 (confirmed with reverse transcription-PCR, data not show) as the agonist antigens for both TCRs (figure 4). The mice bearing tumors were injected with TCR-T cells on day 13 (figure 5A). All tumors volume enlarged on the third day after the injection; however, on the ninth day, they showed different changes. The full-dose of TCR0-T cells $\left(3.0 \times 10^{7}\right)$ produced only slight tumor-suppressive effects that were similar to those found in the mice receiving the low-dose of TCR15-T cells $\left(3.3 \times 10^{6}\right)$. However, the medium-dose of TCR15-T cells $\left(1.0 \times 10^{7}\right)$ produced significant tumor suppression. The mice in this group had only residual tumors detected on day 25, despite the tumors increased to approximately $107 \mathrm{~mm}^{3}$ on day 34 . On the other hand, more than $50 \%(7 / 14)$ and $85 \%(12 / 14)$ of the mice that received the full-dose of TCR15-T cells $\left(3.0 \times 10^{7}\right)$ showed no detectable tumors on day 23 and day 25 , respectively. All tumors were eliminated by day 28 in the full-dose group, and no relapse occurred during an additional 17 days of monitoring. Thus, TCR15-T cells demonstrated superior efficacy and dose-dependent tumor suppression (figure 5B-E). These results confirmed that Ai-TCR-T cells (TCR15-T cells) had a significant advantage over WT-TCR-T cells (TCR0-T cells) in the suppression and elimination of HCC in vivo. 


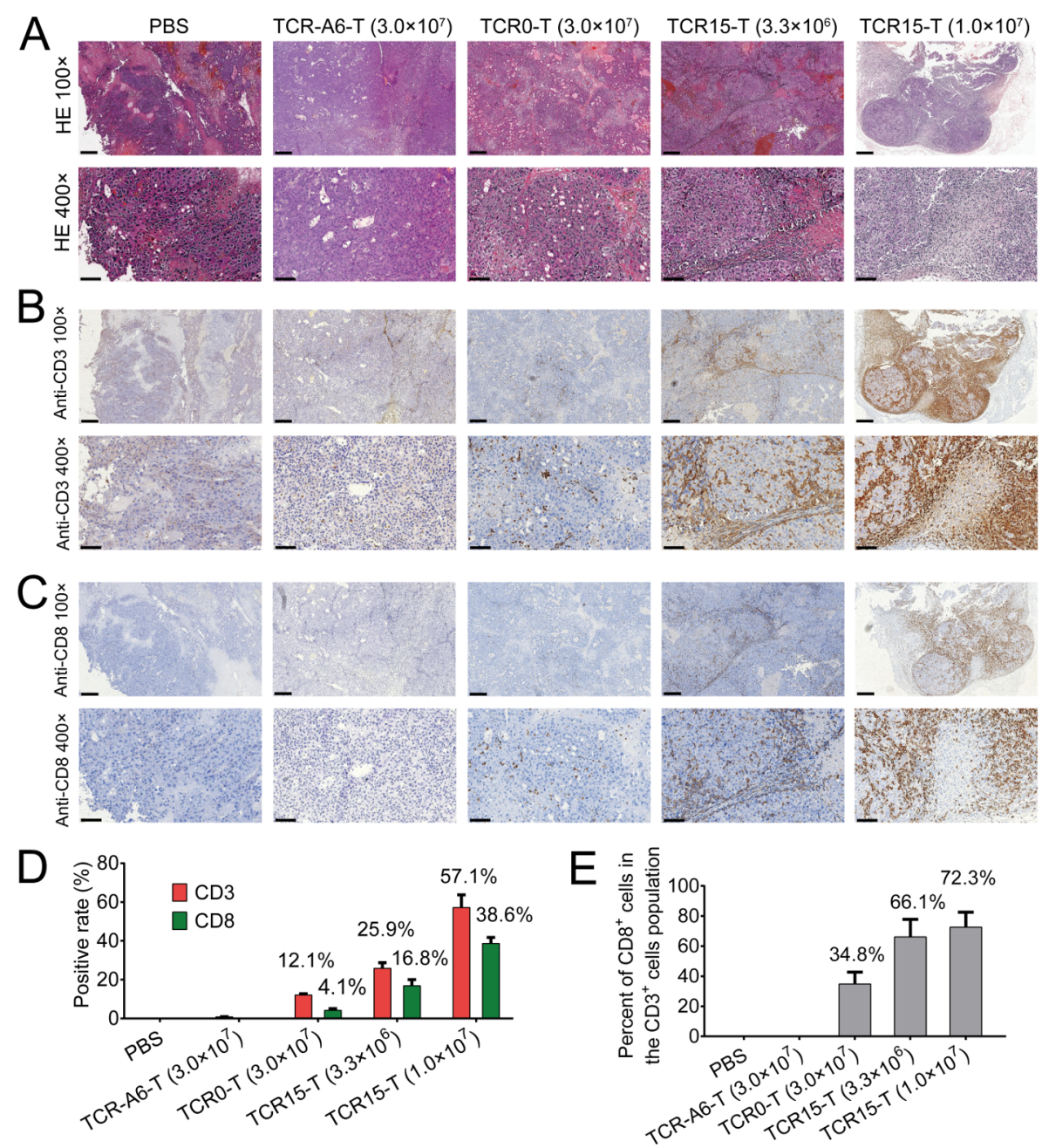

Figure 6 Detection of human T cells in xenograft tumors by H\&E and IHC. Tissue sections of xenograft tumors stained with H\&E or antibodies; the tumors were harvested from animals treated with various reagents including PBS, $3.0 \times 10^{7}$ TCR-A6-T cells, $3.0 \times 10^{7}$ TCRO-T cells, and $3.3 \times 10^{6}$ or $1.0 \times 10^{7}$ TCR15-T cells. Representative images were acquired at $100 \times$ (scale bar, $300 \mu \mathrm{m}$ ) and 400×magnification (scale bar, $90 \mu \mathrm{m}$ ). (A) H\&E staining showing classic HCC morphology. (B) Immunohistochemical staining with anti-CD3 and (C) anti-CD8 antibodies, with positive cells colored brown. (D) Percentages of $C D 3^{+}$and $C D 8^{+} T$ cells in tumor sections. Average positive cells were calculated from six fields at 400xmagnification (online supplemental table S8).

(E) The percentage of $\mathrm{CD}^{+}$cells in the human T cell population detected in the sections. HCC, hepatocellular carcinoma; IHC, immunohistochemistry; PBS, phosphate-buffered solution; TCR, T-cell receptor; TCR-T, TCR-engineered T cell.

\section{TCR15-T cells efficiently infiltrated tumors}

Human $\mathrm{CD}^{+}$and $\mathrm{CD} 8^{+} \mathrm{T}$ cell infiltration was detected in tumor sites by IHC. Examining H\&E-stained (figure 6A) and IHC (figure 6B,C) samples revealed that significant $\mathrm{CD}^{+}$and $\mathrm{CD}^{+} \mathrm{T}$ cell staining was observed in the tumor sections from mice treated with $3.3 \times 10^{6}\left(\mathrm{CD}^{+}: \sim 25.9 \%\right.$ and $\left.\mathrm{CD}^{+}: \sim 16.8 \%\right) \quad$ or $\quad 1.0 \times 10^{7} \quad\left(\mathrm{CD}^{+}: \sim 57.1 \%\right.$ and $\left.\mathrm{CD}^{+}: \sim 38.6 \%\right)$ TCR15-T cells. In contrast, the positive rates for $\mathrm{CD}^{+}$and $\mathrm{CD} 8^{+} \mathrm{T}$ cell populations detected in tumors were only $\sim 12.1 \%$ and $4.1 \%$, respectively, for mice receiving 3-fold or $\sim 10$-fold more TCR0-T cells (figure 6D). It was obvious that elevated TCR15-T cell accumulation occurred in a dose-dependent manner. Furthermore, we found it intriguing that the percent of $\mathrm{CD}^{+}$cells in the $\mathrm{CD}^{+}$cells population was significantly different between the groups. Only $35 \%$ of the human T cells detected in the tumor sections of the mice infused with $3.0 \times 10^{7}$ TCR0-T cells were $\mathrm{CD} 8^{+}$cells. On the other hand, $66 \%$ or $72 \%$ of the human $\mathrm{T}$ cells detected in the tumors of the mice infused with $3.3 \times 10^{6}$ or $1.0 \times 10^{7}$ TCR15-T cells, respectively, were $\mathrm{CD} 8^{+}$cells (figure $6 \mathrm{E}$ ). However, the initial $\mathrm{CD}^{+}$percentages of all tested TCR-T cells, including TCR-A6-T cells, were very similar, with an approximate average of $65.4 \%$ (online supplemental figure S5). The increased $\mathrm{CD}^{+}$populations were consistent with the tumor reduction data for the models. We concluded that a large quantity of $\mathrm{CD} 8^{+} \mathrm{TCR} 15-\mathrm{T}$ cells accumulated in tumor sites.

\section{DISCUSSION}

Treating HBV-related HCC has been a major challenge in the clinic. There are many ways for HCC cells to evade available treatments. One of the fundamental problems is immune escape, which ultimately hinders HCC eradication. In particular, poorly differentiated cells can 
effectively escape by downregulating antigen presentation to avoid CTL attacks, so strategies are needed to address this issue. Immunotherapies have been considered for HCC, HBV antigen-specific TCR-T ${ }^{12}$ and AFPspecific TCR-T therapy ${ }^{40} 41$ are ongoing trials to address these clinic needs. We consider HBV-specific TCR-T can not only treat HCC, may also be used to treat HBV hepatitis with careful manipulated clinic practices.

Although the downregulation of pHLA presentation in tumor cells is well documented in many cancers, ${ }^{42-45}$ whether HCC cells present pHLAs at sufficient levels to activate a CTL response is still under debate. ${ }^{46-49}$ Recent studies by Dr Bertoletti's team demonstrated that HBV antigens could be presented by HCC cells despite these antigens not being detectable by IHC techniques. ${ }^{12}$ In the current study, we demonstrated that an affinity-improved HBsAg-specific TCR could enable T cells to eliminate HCC completely in xenograft mouse models and prevent recurrence. Because high-avidity natural $\mathrm{T}$ cells are common for recognition of a viral antigen, with modest affinity enhancement over the HBsAg specific WT-TCR, TCR15 was sufficient to produce $\mathrm{T}$ cells with significantly improved potency that could eliminate HCC in mice. As the HBs-specific TCR-Ts are able to target HBV epitopes expressed on HBV-infected hepatocytes in addition to HCC cells, to avoid liver failure, HBs-specific TCR-Ts are suggested to treat or prevent HCC relapse in liver transplanted patients.

In an immune synapse, the threshold for triggering the $\mathrm{T}$ cell is determined by the available number of agonist ligands interacting with the TCR cluster formed at the T-cell-target-cell junction. ${ }^{50}$ Every TCR cluster unit requires two or four agonist pMHCs for reaching the activation threshold, ${ }^{50} 51$ which is a requirement that evolved to balance central tolerance towards self-antigens with wild-type TCRs possessing relatively low affinities for pMHCs $\left(\mathrm{K}_{\mathrm{D}}\right.$ in the range of 1 to $\left.100 \mu \mathrm{M}\right) .{ }^{21} \mathrm{The} \mathrm{EC}_{50}$ of TCR0-T cell activation by vrt1-pulsed T2 cells was approximately $6.3 \mathrm{nM}$ (online supplemental figure S2), and this result indicated that effective activation of this TCR might need 50 to 100 pHLAs presented per cell, ${ }^{52}$ which could be reduced further during the cancer development. It offers a chance for HCC to escape attacks by TCR0-T cells. However, it would be difficult for antigen downregulation to enable tumor cells escape from attacks by TCR15-T cells, as these cells had observed approximately 20-fold activation and 40-fold killing enhancements verified in the $\mathrm{EC}_{50}$ (online supplemental figure $\mathrm{S} 2$ ). It is intriguing that the infiltrated the per cent of $\mathrm{CD} 8^{+}$cells in the $\mathrm{CD}^{+}$cells population were $\sim 1 / 3$ for TCR0-T cell-treated animals and $\sim 2 / 3$ for TCR15-T cell-treated animals (figure 6D,E). This may imply that an appropriate TCRpHLA interaction strength will assist $\mathrm{T}$ cell tumor homing and activation. These results also suggested that Ai-TCR-T cells, especially $\mathrm{CD}^{+}$cells, infiltrated better than lowaffinity WT-TCR-T cells in vivo. The efficient expansion of $\mathrm{CD}^{+}$cells in mice resembled observations in clinical investigations with Ai-TCR-T cells targeting the NY-ESO-1 antigen (Yi Li, unpublished data). However, the relation between $\mathrm{CD} 8^{+} \mathrm{T}$ cell infiltration and tumor elimination is still unclear in the current study. Despite almost fourfold more $\mathrm{CD}^{+} \mathrm{T}$ cells detected with Ai-TCR-T cell treatment than with TCR0-T cell treatment, there was no significant improvement in tumor suppression in the mice infused with the low-dose of TCR15-T cells compared with those infused with TCR0-T cells (figures 5D,E and 6D).

It was interesting that the cured mice showed no recurrence during an additional 11-day monitoring after day 34 (figure 5). Another experiment showed no tumor detected on day 14 (more than required days to form detectable tumor mass) after re-inoculation of TCR15-T cell-cured mice with $3.0 \times 10^{6}$ HLA-A $* 02: 01^{+}$PLC/PRF $/ 5$ tumor cells (data not shown). This might indicate that the human $\mathrm{T}$ cells were well maintained during this period.

There are nine HBV genotypes identified, and genotypes $\mathrm{A}$ and $\mathrm{C}$ are the dominant variants in Europe and China, respectively. HBV genotype $\mathrm{C}$ has the highest risk of HCC conversion. ${ }^{32-35} 53$ To generate affinity-improved TCRs for the genotype $\mathrm{C}$ surface antigen, the dominant HBV genotype $\mathrm{B} / \mathrm{C} / \mathrm{D} \mathrm{HBs}_{371-379}$ nonamer vrt1-pHLA was used as the ligand. TCR15 matched the specificity of TCR0, and could cross-react with 11 main HBV antigen variants but not with other potentially cross-reactive human peptides or irrelevant peptides. Based on the epitope frequencies of $\mathrm{HBs}_{371-379}$ and $\mathrm{HBs}_{370-379}$, TCR15 could recognize more than $85 \%$ of HBV variants. These results might help broaden the clinical use of TCR15-T cells.

TCR promiscuity is considered a mechanism for a relatively limited TCR repertoire to deal with the vast diversity of antigenic peptide repertoire. However, when the TCR is modified for affinity enhancement, $\mathrm{T}$ cells may show on-target and/or off-target toxicity. ${ }^{54}$ Extensive screening strategies are necessary to assess the specificity and safety of the TCR-T. In current study, we have used irrelevant peptides, alanine scanning, potentially cross-reactive human peptides, HBV-variant peptides, PBMC and human normal primary cells to verify the specificity and safety of TCR15-T. However, further verification should be in place for the safety of TCR15-T during preclinical study. ${ }^{55} 56$

\section{CONCLUSION}

In summary, the in vitro and in vivo studies demonstrate HBsAg-specific Ai-TCR-T with significantly enhanced potency of HCC treatment, and also showed good safety profiles. We found that Ai-TCR-T were safe with no activity against human normal primary cells, and had good potency showing effective tumor infiltration and tumor clearance in mouse xenograft models. In addition, flexipanning can generate TCR-T cells that cover several HBV antigen variants, which should facilitate the development of TCR-T cell therapy for HCC in a larger population. This is the first example using affinity-improved-TCR to redirect $\mathrm{HBV}$ specific $\mathrm{T}$ cells for addressing the problem 
of HBV-related HCC. Our studies will provide supports for clinical investigations of the Ai-TCR-T for treating HBV associated HCC.

Acknowledgements We acknowledge the advice of Dr Lin Chen and Dr Hongjun Zheng for protein sample assistance. We thank Dr Zhong Su for providing valuable proofreading of the manuscript.

Contributors Contributors QL conceived the study, designed experiment, performed experiments, analyzed data, and wrote the manuscript. YL directed the study and revised the manuscript. YT and YJL assisted with safety testing experiment and provided feedback. YYL, YJL, ZL, PZ and YZ assisted with cell and animal experiments and provided feedback. WZ, YT and YR assisted with hepatitis $B$ virus variants analysis and provided feedback. WC assisted with molecular and biochemical experiment, and provided feedback. YB provided expertise and feedback.

Funding The National Key R\&D Program, 2016YFC1303404; the Science and Technology Program of Guangzhou, 201704020220; the Frontier Research Program of the Guangzhou Regenerative Medicine and Health Guangdong Laboratory, 2018GZR110105010; Project SKLRD-QN-201915 supported by the State Key Laboratory of Respiratory Disease; Project SKLRD-MS-201902 supported by the State Key Laboratory of Respiratory Disease; and the Project of Guangdong Province, 2019A1515010235.

Competing interests None declared.

Patient consent for publication Not required.

Provenance and peer review Not commissioned; externally peer reviewed.

Data availability statement All data relevant to the study are included in the article or uploaded as supplementary information. All data relevant to the study are included in the article or uploaded as supplementary information. The data sets used and/or analyzed during the current study are available from the corresponding author on reasonable request.

Supplemental material This content has been supplied by the author(s). It has not been vetted by BMJ Publishing Group Limited (BMJ) and may not have been peer-reviewed. Any opinions or recommendations discussed are solely those of the author(s) and are not endorsed by BMJ. BMJ disclaims all liability and responsibility arising from any reliance placed on the content. Where the content includes any translated material, BMJ does not warrant the accuracy and reliability of the translations (including but not limited to local regulations, clinical guidelines, terminology, drug names and drug dosages), and is not responsible for any error and/or omissions arising from translation and adaptation or otherwise.

Open access This is an open access article distributed in accordance with the Creative Commons Attribution Non Commercial (CC BY-NC 4.0) license, which permits others to distribute, remix, adapt, build upon this work non-commercially, and license their derivative works on different terms, provided the original work is properly cited, appropriate credit is given, any changes made indicated, and the use is non-commercial. See http://creativecommons.org/licenses/by-nc/4.0/

\section{ORCID iD}

Qi Liu http://orcid.org/0000-0001-6273-9351

\section{REFERENCES}

1 Global Burden of Disease Cancer Collaboration, Fitzmaurice C, Allen $\mathrm{C}$, et al. Global, regional, and National cancer incidence, mortality, years of life lost, years lived with disability, and Disability-Adjusted life-years for 32 cancer groups, 1990 to 2015: a systematic analysis for the global burden of disease study. JAMA Oncol 2017;3:524-48.

2 Bray F, Ferlay J, Soerjomataram I, et al. Global cancer statistics 2018: GLOBOCAN estimates of incidence and mortality worldwide for 36 cancers in 185 countries. CA Cancer J Clin 2018;68:394-424.

3 El-Serag HB. Epidemiology of viral hepatitis and hepatocellular carcinoma. Gastroenterology 2012;142:1264-73.

4 de Martel C, Maucort-Boulch D, Plummer M, et al. World-Wide relative contribution of hepatitis $B$ and $C$ viruses in hepatocellular carcinoma. Hepatology 2015;62:1190-200.

5 Gluer AM, Cocco N, Laurence JM, et al. Systematic review of actual 10 -year survival following resection for hepatocellular carcinoma. HPB 2012;14:285-90.

6 Faria LC, Gigou M, Roque-Afonso AM, et al. Hepatocellular carcinoma is associated with an increased risk of hepatitis $B$ virus recurrence after liver transplantation. Gastroenterology 2008;134:1890-9.

7 Gehring AJ, Ho ZZ, Tan AT, et al. Profile of tumor antigen-specific CD8 T cells in patients with hepatitis B virus-related hepatocellular carcinoma. Gastroenterology 2009;137:682-90.

8 June $\mathrm{CH}$. Adoptive T cell therapy for cancer in the clinic. J Clin Invest 2007;117:1466-76.

9 Brechot C, Pourcel C, Louise A, et al. Presence of integrated hepatitis $B$ virus DNA sequences in cellular DNA of human hepatocellular carcinoma. Nature 1980;286:533-5.

10 Dhanasekaran R, Nault J-C, Roberts LR, et al. Genomic medicine and implications for hepatocellular carcinoma prevention and therapy. Gastroenterology 2019;156:492-509.

11 Buschow SI, Sprengers D, Woltman AM. To target or not to target viral antigens in HBV related HCC? J Hepatol 2015;62:1449-50.

12 Tan AT, Yang N, Lee Krishnamoorthy T, et al. Use of expression profiles of HBV-DNA integrated into genomes of hepatocellular carcinoma cells to select T cells for immunotherapy. Gastroenterology 2019;156:1862-76.

13 Qasim W, Brunetto M, Gehring AJ, et al. Reply to: "To target or not to target viral antigens in HBV related HCC?". J Hepatol 2015;62:1450-2.

14 Gehring AJ, Xue S-A, Ho ZZ, et al. Engineering virus-specific T cells that target HBV infected hepatocytes and hepatocellular carcinoma cell lines. J Hepatol 2011;55:103-10.

15 Koh S, Shimasaki N, Suwanarusk R, et al. A practical approach to immunotherapy of hepatocellular carcinoma using $T$ cells redirected against hepatitis B virus. Mol Ther Nucleic Acids 2013;2:e114.

16 Banu N, Chia A, Ho ZZ, et al. Building and optimizing a virus-specific T cell receptor library for targeted immunotherapy in viral infections. Sci Rep 2014;4:4166.

17 Qasim W, Brunetto M, Gehring AJ, et al. Immunotherapy of HCC metastases with autologous T cell receptor redirected T cells, targeting HBsAg in a liver transplant patient. $J$ Hepatol 2015;62:486-91.

18 Koh S, Tan AT, Li L, et al. Targeted therapy of hepatitis B virus-related hepatocellular carcinoma: present and future. Diseases 2016;4:10.

19 Wang Y, Wu M-C, Sham JST, et al. Different expression of hepatitis $B$ surface antigen between hepatocellular carcinoma and its surrounding liver tissue, studied using a tissue microarray. J Pathol 2002;197:610-6.

20 Tantiwetrueangdet A, Panvichian R, Sornmayura P, et al. Reduced $\mathrm{HBV}$ cccDNA and HBsAg in HBV-associated hepatocellular carcinoma tissues. Med Oncol 2018;35:127.

21 van der Merwe PA, Davis SJ. Molecular interactions mediating T cell antigen recognition. Annu Rev Immunol 2003;21:659-84.

22 Li Y, Moysey R, Molloy PE, et al. Directed evolution of human T-cell receptors with picomolar affinities by phage display. Nat Biotechnol 2005;23:349-54.

23 Varela-Rohena A, Molloy PE, Dunn SM, et al. Control of HIV-1 immune escape by CD8 T cells expressing enhanced T-cell receptor. Nat Med 2008;14:1390-5.

24 Liddy N, Bossi G, Adams KJ, et al. Monoclonal TCR-redirected tumor cell killing. Nat Med 2012;18:980-7.

25 Rapoport AP, Stadtmauer EA, Binder-Scholl GK, et al. NY-ESO-1specific TCR-engineered T cells mediate sustained antigen-specific antitumor effects in myeloma. Nat Med 2015;21:914-21.

26 Robbins PF, Kassim SH, Tran TLN, et al. A pilot trial using lymphocytes genetically engineered with an NY-ESO-1-reactive T-cell receptor: long-term follow-up and correlates with response. Clin Cancer Res 2015;21:1019-27.

27 McNaughton AL, D'Arienzo V, Ansari MA, et al. Insights from deep sequencing of the HBV Genome-Unique, tiny, and misunderstood. Gastroenterology 2019;156:384-99.

28 Selin LK, Welsh RM. Plasticity of T cell memory responses to viruses. Immunity 2004;20:5-16.

29 Hao Y, Legrand N, Freitas AA. The clone size of peripheral CD8 T cells is regulated by TCR promiscuity. J Exp Med 2006;203:1643-9.

30 Hoof I, Pérez CL, Buggert M, et al. Interdisciplinary analysis of HIV-specific CD8+ T cell responses against variant epitopes reveals restricted TCR promiscuity. J Immunol 2010;184:5383-91.

31 Zanker D, Quinn K, Waithman J, et al. T cells recognizing a $11 \mathrm{mer}$ influenza peptide complexed to $\mathrm{H}-2 \mathrm{D}(\mathrm{b})$ show promiscuity for peptide length. Immunol Cell Biol 2015;93:500-7.

32 Sumi H, Yokosuka O, Seki N, et al. Influence of hepatitis B virus genotypes on the progression of chronic type $\mathrm{B}$ liver disease. Hepatology 2003;37:19-26.

33 Yu M-W, Yeh S-H, Chen P-J, et al. Hepatitis B virus genotype and DNA level and hepatocellular carcinoma: a prospective study in men. J Nat/ Cancer Inst 2005;97:265-72. 
34 Yang $\mathrm{H}-\mathrm{I}$, Yeh S-H, Chen P-J, et al. Associations between hepatitis B virus genotype and mutants and the risk of hepatocellular carcinoma. J Natl Cancer Inst 2008;100:1134-43.

35 Liu S, Zhang H, Gu C, et al. Associations between hepatitis B virus mutations and the risk of hepatocellular carcinoma: a meta-analysis. J Natl Cancer Inst 2009;101:1066-82.

36 Haase K, Raffegerst S, Schendel DJ, et al. Expitope: a web server for epitope expression. Bioinformatics 2015;31:1854-6.

37 Jaravine V, Mösch A, Raffegerst S, et al. Expitope 2.0: a tool to assess immunotherapeutic antigens for their potential crossreactivity against naturally expressed proteins in human tissues. BMC Cancer 2017;17:892.

38 Zhang H, Zhang J, Chen L, et al. Targeting naturally occurring epitope variants of hepatitis $\mathrm{C}$ virus with high-affinity T-cell receptors. $J$ Gen Virol 2017;98:374-84

39 Ye W, Jiang Z, Li G-X, et al. Quantitative evaluation of the immunodeficiency of a mouse strain by tumor engraftments. $J$ Hematol Oncol 2015;8:59.

40 Zhu W, Peng Y, Wang L, et al. Identification of $\alpha$-fetoprotein-specific T-cell receptors for hepatocellular carcinoma immunotherapy. Hepatology 2018;68:574-89.

41 Docta RY, Ferronha T, Sanderson JP, et al. Tuning T-cell receptor affinity to optimize clinical risk-benefit when targeting AlphaFetoprotein-Positive liver cancer. Hepatology 2019;69:2061-75.

42 Ogino $\mathrm{T}$, Shigyo $\mathrm{H}$, Ishii $\mathrm{H}$, et al. Hla class I antigen down-regulation in primary laryngeal squamous cell carcinoma lesions as a poor prognostic marker. Cancer Res 2006;66:9281-9.

43 Kageshita T, Ishihara T, Campoli M, et al. Selective monomorphic and polymorphic HLA class I antigenic determinant loss in surgically removed melanoma lesions. Tissue Antigens 2005;65:419-28.

44 Hicklin DJ, Marincola FM, Ferrone S. Hla class I antigen downregulation in human cancers: T-cell immunotherapy revives an old story. Mol Med Today 1999;5:178-86.

45 Lei W-Y, Hsiung S-C, Wen S-H, et al. Total HLA class I antigen loss with the downregulation of antigen-processing machinery components in two newly established Sarcomatoid hepatocellular carcinoma cell lines. J Immunol Res 2018;2018:1-12.

46 Kurokohchi K, Carrington M, Mann DL, et al. Expression of HLA class I molecules and the transporter associated with antigen processing in hepatocellular carcinoma. Hepatology 1996;23:1181-8.

47 Fujiwara K, Higashi T, Nouso K, et al. Decreased expression of B7 costimulatory molecules and major histocompatibility complex class-I in human hepatocellular carcinoma. J Gastroenterol Hepatol 2004;19:1121-7.

48 Shen Y, Xia M, Zhang J, et al. Irf-1 and p65 mediate upregulation of constitutive HLA-A antigen expression by hepatocellular carcinoma cells. Mol Immunol 2009;46:2045-53.

49 Zhou J, Ma P, Li J, et al. Improvement of the cytotoxic T lymphocyte response against hepatocellular carcinoma by transduction of cancer cells with an adeno-associated virus carrying the interferon- $\gamma$ gene. Mol Med Rep 2016;13:3197-205.

50 Dustin ML, Depoil D. New insights into the T cell synapse from single molecule techniques. Nat Rev Immunol 2011;11:672-84.

51 Manz BN, Jackson BL, Petit RS, et al. T-Cell triggering thresholds are modulated by the number of antigen within individual T-cell receptor clusters. Proc Natl Acad Sci U S A 2011;108:9089-94.

52 Bossi G, Gerry AB, Paston SJ, et al. Examining the presentation of tumor-associated antigens on peptide-pulsed T2 cells. Oncoimmunology 2013;2:e26840.

53 McMahon BJ. The natural history of chronic hepatitis B virus infection. Hepatology 2009;49:S45-55.

54 Bijen HM, van der Steen DM, Hagedoorn RS, et al. Preclinical strategies to identify off-target toxicity of high-affinity TCRs. Mol Ther 2018;26:1206-14.

55 Border EC, Sanderson JP, Weissensteiner T, et al. Affinity-enhanced T-cell receptors for adoptive T-cell therapy targeting MAGE-A10: strategy for selection of an optimal candidate. Oncoimmunology 2019;8:e1532759.

56 Coles $\mathrm{CH}$, Mulvaney RM, Malla S, et al. TCRs with distinct specificity profiles use different binding modes to engage an identical PeptideHLA complex. J Immunol 2020;204:1943-53. 